\title{
Alterations in distribution and composition of the extracellular matrix during decidualization of the human endometrium
}

\author{
M. Iwahashi ${ }^{1}$, Y. Muragaki ${ }^{2}$, A. Ooshima ${ }^{2}$, M. Yamoto ${ }^{1}$ and \\ R. Nakano ${ }^{1 *}$ \\ ${ }^{1}$ Department of Obstetrics and Gynaecology and ${ }^{2}$ Department of Pathology, Wakayama Medical College, \\ Wakayama 640, Japan
}

\begin{abstract}
The distribution of the extracellular matrix, including type I, III, IV and VI collagens and laminin, and of prolyl hydroxylase was investigated in the human endometrium by an indirect immunofluorescence method with specific monoclonal antibodies. Collagens were also extracted from the endometrial tissues in the proliferative and secretory phases and from the decidual tissues in the first trimester of pregnancy. Immunohistochemical studies demonstrated that interstitial collagens, such as type I, III, and VI collagens, were localized diffusely in the stroma of the endometrium throughout the menstrual cycle, as well as in the decidua. Type IV collagen and laminin were localized exclusively in the basement membrane of the endometrial glands and in the walls of blood vessels during the proliferative and secretory phases. However, strong staining for type IV collagen and laminin was recognized in the pericellular region of endometrial stromal cells in the decidua. Prolyl hydroxylase was localized in the cytoplasm of endometrial stromal cells and endometrial glandular cells during the menstrual cycle. Intense immunostaining for prolyl hydroxylase was observed in the decidual cells. However, immunoreactivity for prolyl hydroxylase in the endometrial glandular cells disappeared during the process of decidualization. The ratio of type III to type I collagen was significantly decreased $(P<0.05)$ and the ratio of type $V$ to type I collagen was significantly increased $(P<0.01)$ in the decidua, as compared with ratios in the endometrium during the proliferative phase. The present results suggest that changes in the extracellular matrix may play an important role in implantation, in invasion of trophoblastic cells and in the maintenance of pregnancy.
\end{abstract}

\section{Introduction}

The extracellular matrix (ECM) is considered to play an important role in the stability of tissue structure and in the regulation of cell growth and differentiation (Labat-Robert et al., 1990; Madri and Basson, 1992; Lin and Bissell, 1993). Indeed, the synthesis, accumulation and catabolism of ECM are involved in wound healing and in the initiation and progression of several diseases, such as atherosclerosis, liver fibrosis, glomerulosclerosis, glomerulonephritis, scleroderma, and pulmonary fibrosis (Haralson, 1993).

During the menstrual cycle and early pregnancy, pronounced morphological changes occur in the human endometrium under the control of ovarian hormones, which include oestrogen and progestin (Strauss and Gurpide, 1991). Endometrial tissues are considered to play a role in implantation of the embryo, control of trophoblast invasion (Pijnenborg et al., 1980), nutrition of the blastocyst (Kearns and Lala, 1983), secretion of prolactin (Maslar et al., 1980; Daly et al., 1983), protection of the embryo from the maternal immune system

${ }^{*}$ Correspondence.

Received 4 March 1996
(Golander $e$ al., 1981), and the synthesis of ECM (Juan $e$ al., 1989). Appropriate changes in the quantity and composition of ECM, as well as the relationship between the ECM and endometrial cells, must surely be essential for implantation of the embryo, invasion of trophoblastic cells into the decidualized endometrium, and the maintenance of pregnancy. Collagens and laminin are major components of the ECM. Research into collagen in the past decade has resulted in the identification of at least 19 different types of collagen plus numerous other nonstructural proteins that contain at least one collagen triple helix as a structural motif (Van der Rest and Garrone, 1991); all of which are regarded as members of a collagen superfamily (Hulmes, 1992). Interstitial and basement membrane collagens, glycoproteins, and proteoglycans in the endometrium have been reported to change markedly with changes in hormone concentrations (Aplin et al., 1988). However, little is known about alterations in the distribution and composition of the ECM in the human endometrium and decidua. In the present study, therefore, we investigated changes in the distribution of the ECM by an indirect immunofluorescence method using specific antibodies directed against the various components of the ECM, including type I, III, IV, and VI collagens and laminin, and using a specific antibody 
against prolyl hydroxylase, which is a key enzyme in the synthesis of collagen (Rhoads and Udenfriend, 1970; Cardinale and Udenfriend, 1974). We also discuss the relative amounts of various collagens in the endometrial tissues in the proliferative and secretory phases and in the decidual tissues during the first trimester of pregnancy.

Type $\mathrm{V}$ collagen is a very poor immunogen against which it has been difficult to prepare reliable specific antibodies. Therefore, we evaluated the change in the relative amount of this collagen in the endometrium from the proliferative phase to early pregnancy.

\section{Materials and Methods}

\section{Tissues}

Human endometrial tissues were obtained by endometrial biopsy and hysterectomy for gynaecologic indications, such as uterine myoma, and were immediately frozen in liquid nitrogen. Decidual tissues were obtained by dilatation and curettage for termination of pregnancy. The project was approved by the Committee on Investigations Involving Human Subjects of Wakayama Medical College. Informed consent was obtained from each woman after the purpose and nature of the study had been fully explained. The endometrial phase was determined by the timing of the last menstrual period, the records of basal body temperature, and the histology. We excluded endometrial tissues in which obvious inflammation was present. Thirty-six samples of proliferative-phase endometrium, 42 samples of secretory-phase endometrium, and 53 samples of decidual tissues from early pregnancies ( 7 to 12 weeks) were examined. Gestational age was determined from the date of the last menstrual period and ultrasonographic measurements during early pregnancy.

\section{Primary antibodies}

Monoclonal antibodies (mAbs) against human type I, III, IV and VI collagens were used for this study. Preparation of the antibodies has been described by Ooshima and Muragaki (1990). In brief, BALB/C mice were immunized with each collagen, which had been extracted from human placentas. The spleen cells were hybridized with myeloma cells. After HAT (hypoxanthine-aminopterine-thymidine) selection, positive hybrids were screened by enzyme-linked immunosorbent assay. The specificity of each antibody was determined by an immunoblot or inhibition enzyme-linked immunosorbent assay. No crossreaction was recognized among the antibodies against each human collagen. Polyclonal antibodies against human laminin were purchased from Gibco Lab. Co. (Grand Island, NY). The laminin-specific antibody also showed no crossreaction with type I, III, IV, and VI collagens or fibronectin. Monoclonal antibodies against prolyl hydroxylase (anti$\mathrm{hPH}(\beta)$; horseradish peroxidase-conjugated Fab' (Fab'-HRP)), which recognized the $\beta$ subunit of prolyl 4-hydroxylase, were prepared as described by Bai et al. (1986).

\section{Immunohistochemistry}

Immunohistochemistry was performed by the indirect immunofluorescence method. In brief, $3 \mu \mathrm{m}$ frozen sections were rehydrated in PBS at room temperature and then incubated with the primary antibody ( $1: 100$ diluted in PBS) at $4{ }^{\circ} \mathrm{C}$ for $12 \mathrm{~h}$ in a humidified chamber. After incubation, the sections were washed twice in PBS for $3 \mathrm{~min}$. Each slide was then incubated at room temperature for $1 \mathrm{~h}$ with human plasma-preabsorbed, fluorescein isothiocyanate-conjugated goat antibodies against mouse immunoglobulins or goat antibodies against rabbit immunoglobulins that had been diluted 1:100 (Organon Teknik, Co., West Chester, PA). The sections were washed again in PBS, mounted in buffered glycerol and examined under a fluorescence microscope (Olympus Co., Tokyo). Control sections were stained with goat antibodies against mouse immunoglobulin $\mathrm{G}$ (secondary antibodies) without prior application of the appropriate primary antibody. When the mAbs were first absorbed with an excess of each type of collagen, laminin or prolyl hydroxylase, as appropriate, no immunostaining was observed (data not shown).

\section{SDS-PAGE of pepsin-solubilized collagens from the human endometrium}

Minced samples of human endometrium were washed overnight in cold distilled water and freed of blood. Tissues were homogenized with a Polytron homogenizer in 50 volumes of 0.5 mol acetic acid $\mathrm{l}^{-1}$ that contained $1 \mathrm{mg}$ pepsin $\mathrm{ml}^{-1}$ (Sigma Chemical Co. St Louis, MO). Collagens were extracted with constant stirring for $24 \mathrm{~h}$ at $4^{\circ} \mathrm{C}$. The solutions were centrifuged at $39000 \mathrm{~g}$ for $1 \mathrm{~h}$ at $4^{\circ} \mathrm{C}$. Collagens were re-extracted from the pellets under the same conditions for $48 \mathrm{~h}$. The supernatants were then combined and collagens were precipitated by addition of $4.0 \mathrm{~mol} \mathrm{NaCl} \mathrm{l} \mathrm{N}^{-1}$ to a final concentration of $2.0 \mathrm{~mol} \mathrm{l}^{-1}$. The precipitate was dissolved in $0.5 \mathrm{~mol}$ acetic acid $1^{-1}$ and dialysed against $0.02 \mathrm{~mol}$ $\mathrm{Na}_{2} \mathrm{HPO}_{4} \mathrm{l}^{-1}$. Precipitated collagens were redissolved in 0.5 mol acetic acid $l^{-1}$, dialysed exhaustively against $0.05 \mathrm{~mol}$ acetic acid $\mathrm{I}^{-1}$ and finally lyophilized. The solubility of the tissue collagen from each endometrial sample was estimated by comparing the hydroxyproline content of the initial homogenate with that of the final solution of collagen (Kivirikko and Prockop, 1967). Type V collagen was isolated by salt precipitation from pepsin digests of human decidual tissues by the methods described elsewhere (Furuto and Miller, 1980; Miller and Rhodes, 1982). The extracted type $\mathrm{V}$ collagen was also lyophilized. Estimation of the relative abundance of the $\alpha$ I(III) chain and the $\alpha 1(V)$ chain was performed by interrupted gel electrophoresis (Sykes et al., 1976). Electrophoresis was performed in an $8 \%$ polyacrylamide gel slab (Sigma Chemical Co.). The gel and electrode buffers were 0.1 mol phosphate buffer $\mathrm{l}^{-1}$, pH 7.2, containing $0.1 \%(\mathrm{w} / \mathrm{v})$ SDS (Nacalai Tesque Inc., Kyoto), as described by Laemmli (1970). Lyophilized samples of collagens and type $\mathrm{V}$ collagen were dissolved at a concentration of $0.2 \mathrm{mg} \mathrm{ml}^{-1}$ and denatured by heating in the gel buffer that contained $1 \%(\mathrm{w} / \mathrm{v}) \mathrm{SDS}$ at $60^{\circ} \mathrm{C}$ for $30 \mathrm{~min}$.

Aliquots of $25 \mu \mathrm{l}$ of solutions of denatured collagens and $5 \mu \mathrm{l}$ of denatured type $\mathrm{V}$ collagen were applied to the gel and subjected to electrophoresis at $80 \mathrm{~mA}$. After $1.5 \mathrm{~h}$ the current was switched off and sample wells were filled with $20 \%(\mathrm{w} / \mathrm{v})$ $\beta$-mercaptoethanol (Wako Chemical Co., Osaka), which was allowed to diffuse into the gel for $1 \mathrm{~h}$ to cleave intramolecular 
disulfide bonds of type III collagen $[\alpha I(\mathrm{III})]_{3}$. Then electrophoresis was resumed and allowed to continue for $1 \mathrm{~h}$. Each collagen $\alpha$ chain was stained with Coomassie brilliant blue (Sigma Chemical Co.) and quantitated by densitometry. The relative amounts of $\alpha 1(\mathrm{III})$ or $\alpha 1(\mathrm{~V})$ chains were calculated by dividing the intensities of bands of $\alpha I($ III) and $\alpha I(V)$ by that of $a l(l)$.

\section{Statistical analysis}

The ratio of $\alpha I(\mathrm{III})$ to $\alpha I(\mathrm{I})$ chains and that of $\alpha \mathrm{I}(\mathrm{V})$ to $\alpha I(\mathrm{I})$ chains, as estimated by densitometry, were represented as means \pm SEM, and they were analysed by analysis of variance and Student's $t$ test.

\section{Results}

\section{Immunohistochemical analysis of the endometrium and decidua}

Enhanced immunostaining with the mAbs against type I (Fig. Ia, b) and type IIl (Fig. Id, e) collagens was observed with a fibrillar pattern in the stroma of the endometrium and in the vessel walls throughout the menstrual cycle. Immunostaining with the $\mathrm{mAb}$ against type VI collagen was also recognized in the stroma of the endometrium during the menstrual cycle, with a fine fibrillar pattern (Fig. Ig, h). In the decidual tissue, there was strong immunostaining with $\mathrm{mAbs}$ against type I, III, and VI collagens in the matrix between decidual cells and in the vessel walls (Fig. $I c, f, i)$. By contrast, no immunostaining for type I, ilI, and VI collagens was observed in endometrial glands.

Immunostaining with the $\mathrm{mAb}$ against type IV collagen was observed exclusively on the basement membrane of endometrial glands and beneath the endothelial cells of capillaries throughout the menstrual cycle (Fig. 2a, b). In decidual tissues, by contrast, type IV collagen was observed in the pericellular region around the decidual cells with strong immunofluorescence (Fig. 2c, g). Immunoreactive staining with the specific antibodies against laminin was observed on the basement membrane of the endometrial glands and beneath the endothelial cells of capillaries (Fig. 2d, e). Strong immunofluorescence specific for laminin was observed in the pericellular aura of the decidual cells with a similar pattern of staining to that of type IV collagen (Fig. 2f, h).

Throughout the menstrual cycle, the stromal cells of the endometrium exhibited positive immunoreactivity for prolyl hydroxylase as a fine granular pattern in the cytoplasm (Fig. 3a,b). The epithelial cells of the endometrial glands (Fig. 3a, b) and the endothelial cells of vessels (Fig. 3c) were also immunopositive for prolyl hydroxylase. Moreover, enhanced immunoreactivity specific for prolyl hydroxylase in the cytoplasm of the decidual cells gave a fine granular pattern (Fig. 3c). In the decidua, however, only weak immunofluorescence in the epithelial cells of endometrial glands was detected (Fig. 3d).

\section{Interrupted SDS-PAGE of pepsin-solubilized collagens from the endometrium and decidua}

The interrupted SDS-PAGE revealed that the relative amounts of $\alpha I(V)$ and $\alpha I(I)$ increased and that of $\alpha I(I I)$ decreased from the proliferative-phase endometrium to the decidua (Fig. 4). The ratios of intensities of bands of $\alpha 1$ (III) to $\alpha I(\mathrm{I})$ (Fig. 5a) and $\alpha I(\mathrm{~V})$ to $\alpha I(\mathrm{I})$ (Fig. $5 \mathrm{~b}$ ) were $0.76 \pm 0.03$, $0.47 \pm 0.09,0.37 \pm 0.04$, and $0.033 \pm 0.014,0.057 \pm 0.015$, $0.107 \pm 0.010$ (mean \pm SEM) in the proliferative-phase endometrium, the secretory-phase endometrium, and in the decidua, respectively. The ratios of intensities of bands of $\alpha$ I(III) to $\alpha I$ (I) in the secretory-phase endometrium and the decidua were significantly lower than that in the proliferative-phase endometrium $(P<0.05)$. Furthermore, the ratio of intensities of $\alpha 1(V)$ to $\alpha I(I)$ in the decidua was significantly higher than that in the proliferative-phase endometrium $(P<0.01)$ and than that in the secretory-phase endometrium $(P<0.05)$.

\section{Discussion}

In the present study, we investigated changes in the distribution and composition of the ECM, including type I, III, IV, V and VI collagens and laminin, as well as in the distribution of prolyl hydroxylase, in the human endometrium throughout the menstrual cycle and in the decidua during early pregnancy. We were able to solubilize $70-85 \%$ of collagen in the human endometrial and decidual tissues, as measured by reference to amounts of hydroxyproline present (data not shown). Therefore, it was postulated that the extracted collagen accurately reflects the entire complement of collagen in the tissues.

The presence of interstitial collagens, such as type I, III, and VI collagens, was confirmed immunohistochemically in the endometrium throughout the menstrual cycle and in the decidua. Type I and type III collagens were distributed in a diffuse and fibrillar pattern in both the proliferative-phase and secretory-phase endometrium and were more tightly packed between the decidual cells. Although type I and type III collagens are commonly found in combination, the ratio of type III to type I collagen in the proliferative-phase endometrium was significantly higher than the ratios in the secretory-phase endometrium and decidua. Changes in the ratio of type III to type I collagen have been demonstrated in human skin (Sykes et al., 1976) and in human atherosclerosis (McCullagh and Balian, 1975; Ooshima, 1981). A possible cause of the change in the composition of the ECM may be an alteration in the hormonal environment, which includes oestrogen and progestin. Another cause may be an alteration in the density of cells in the human endometrium. Cell densitydependent effects have been reported in the various types of cell, such as mesangial cells (Ishimura et al., 1989; Lermioglu et al., 1991; Worthuis et al., 1993), endothelial cells (Patton et al., 1990), vascular smooth muscle cells (Campbell et al., 1989; Goodman and Majack, 1989; Majors and Ehrhart, 1992), fibroblasts (Halme et al., 1986; Rösner et al., 1990), and primitive mesenchymal cells (Tsonis and Goetinck, 1990). It has been suggested that cell density modulates biological behaviour, with changes in signal-transduction responses to hormonal stimulation, in growth, in the synthesis and composition of the ECM, and in the synthesis of specific proteins (Ishimura et al., 1989; Lermioglu et al., 1991; Worthuis et al., 1993). Worthuis et al. (1993) reported that mesangial cells synthesized relatively more type I collagen per cell at higher cell densities, whereas synthesis of type III and type IV 

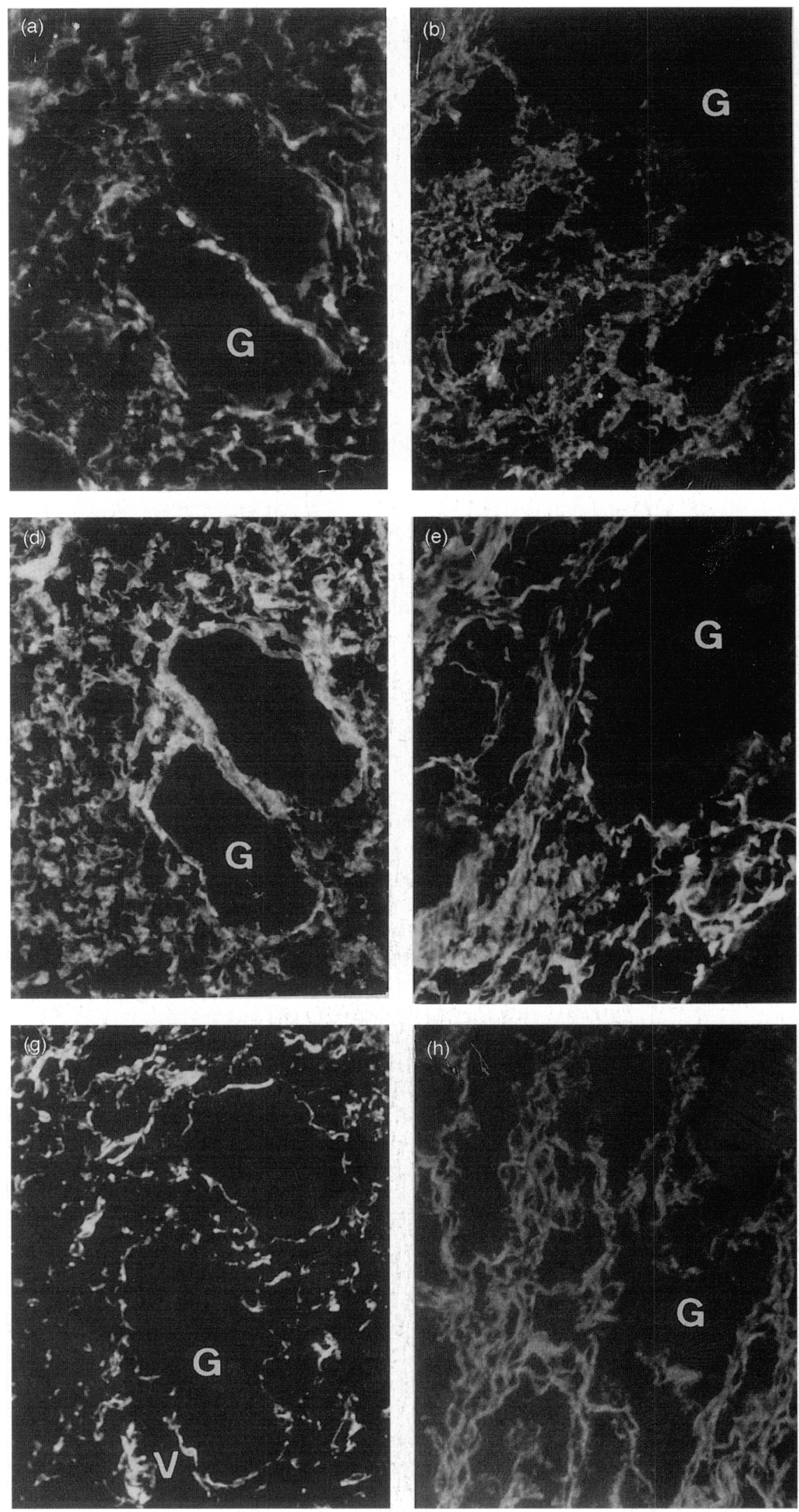
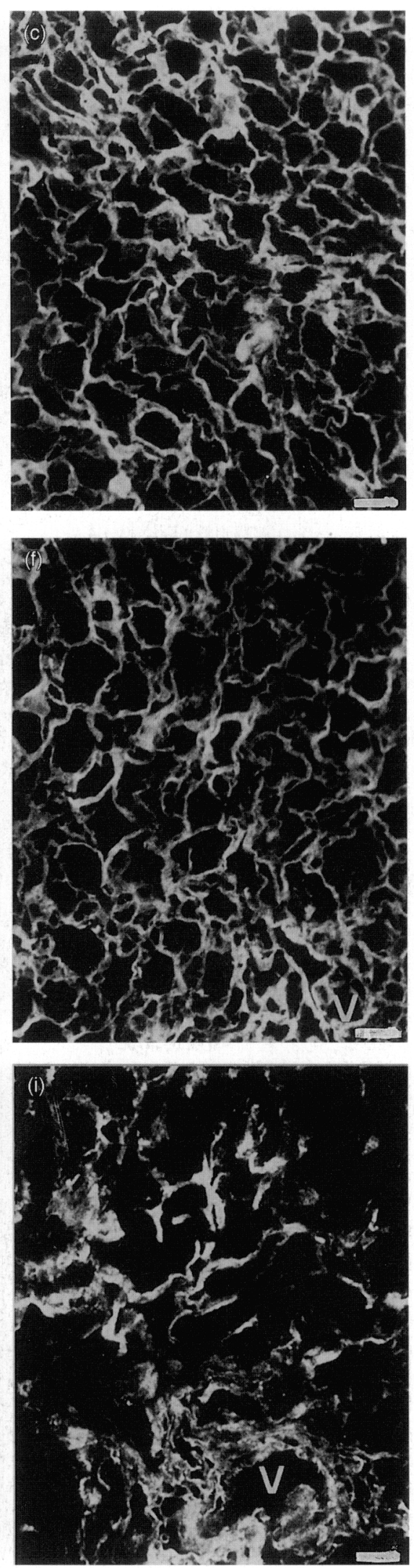

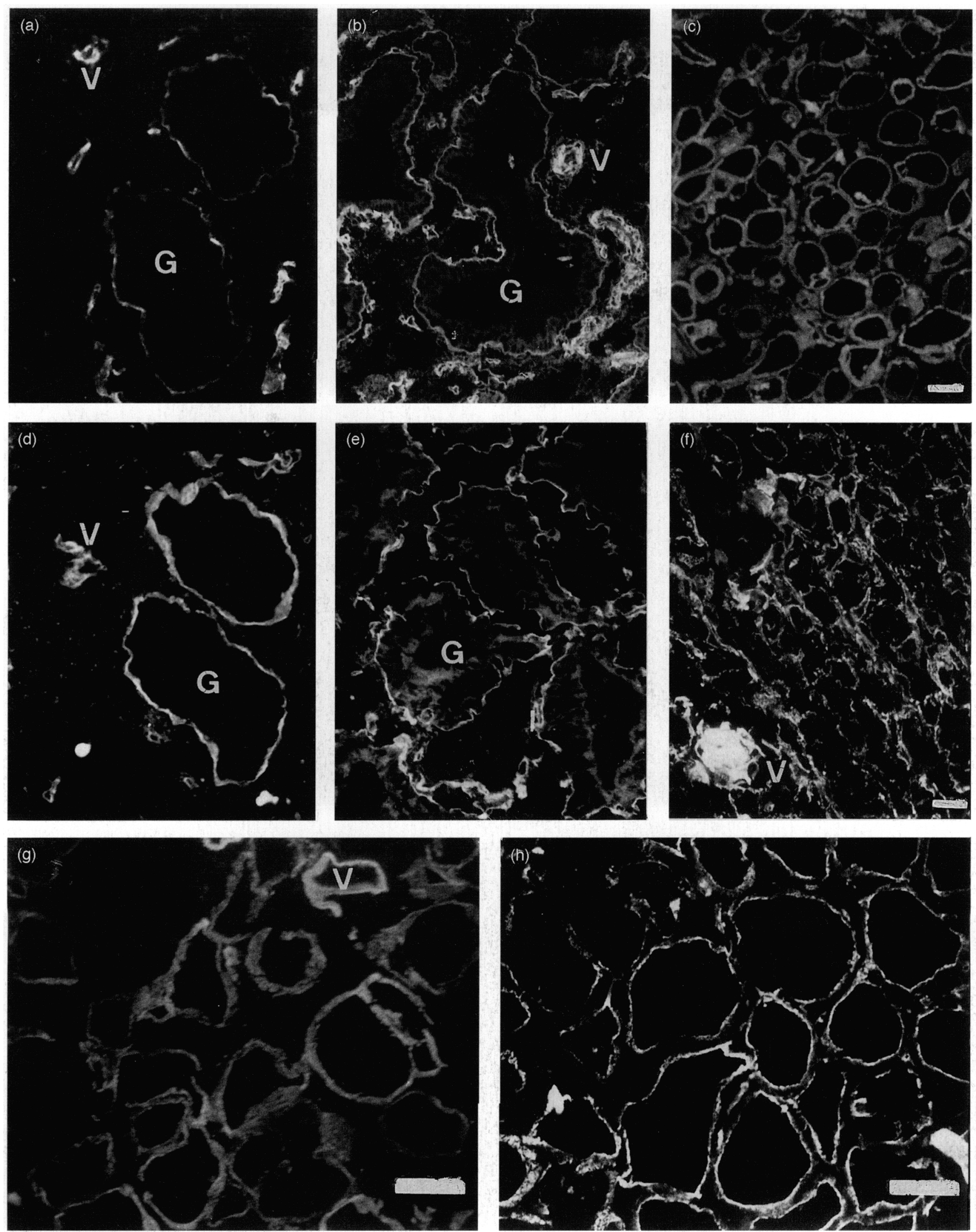

Fig. 2. Immunofluorescence micrographs of human endometrum and decidua stained with a monoclonal antibody specific for collagen type IV $i a-c, g)$ and polyclonal antibodies against laminin $(d-f, h)$ iproliferative-phase endonetrium: a, $d$; secretory-phase endometrium: $b$, e; decidual tissuc: $c$. f, g. h. In the proliferative-phase and secretory-phase endometrium, type IV collagen and laminin were localized exclusively in the basement membranes of endometrial glands $(G)$ and blood vessels $(V)$. In the decidua, intense immumostaining for type IV collagen and laminin was recognized in the pericellutar region of decidual cells. Scale bars represent $50 \mu \mathrm{m}$. 

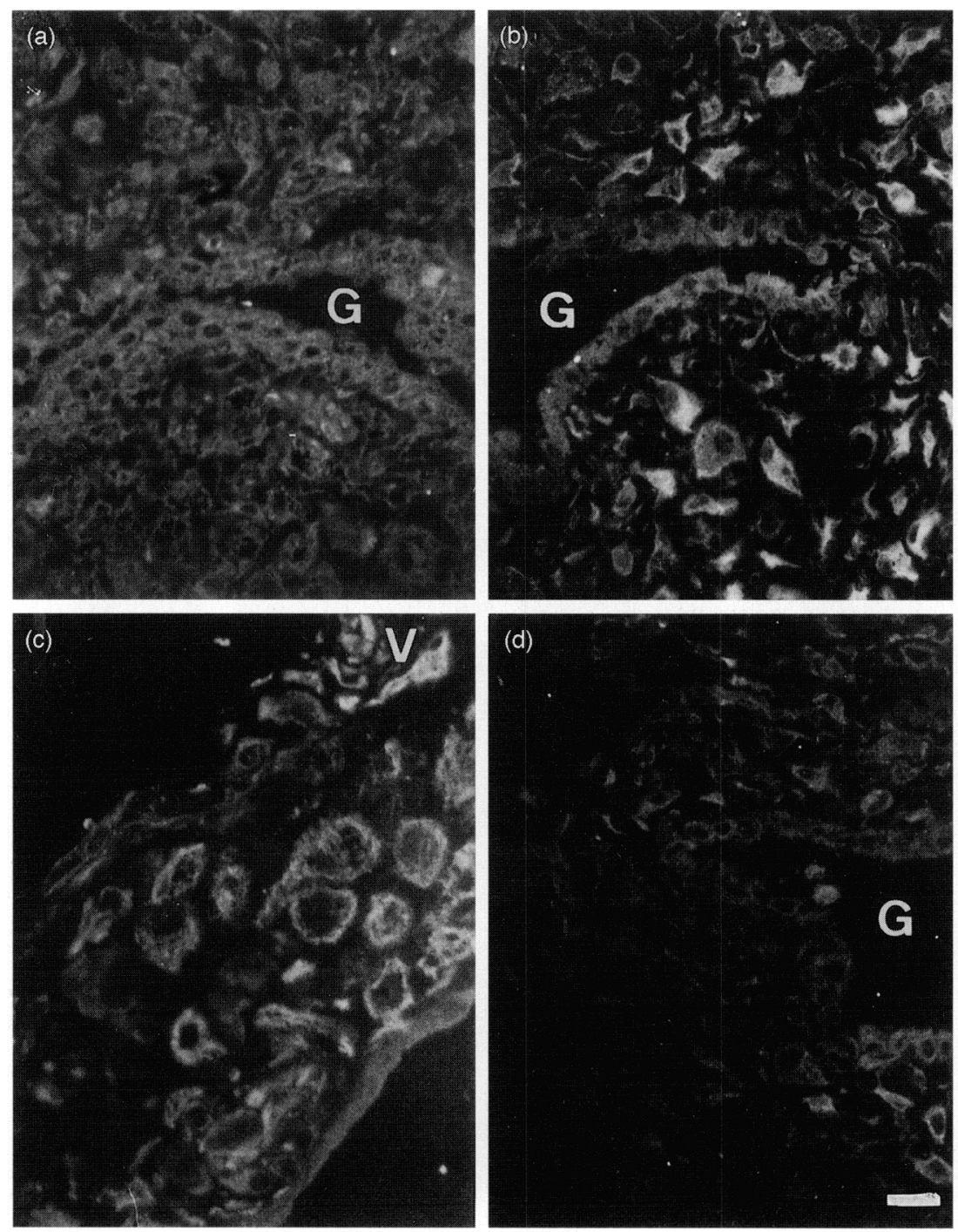

Fig. 3. Immunofluorescence staining for human prolyl hydoxylase in the secretory-phase endometrium and decidual tissue (proliferative-phase endometrium: a; secretory-phase endometrium: b; decidual tissue: c, d). Immunostaining was observed in the endometrial stromal and glandular cells in the proliferative and secretory-phase endometrium ( $a, b$ ). Decidual cells showed enhanced immunostaining for prolyl hydroxylase (c). Endometrial glandular celss showed very weak or no immunofluorescence in the decidua (d). G: endometrial gland; $V$ : blood vessels. Scale bar represents $50 \mu \mathrm{m}$.

collagens in each cell did not depend on cell density. Therefore, it is suggested that ovarian secretion of oestrogen causes intense proliferation of the endometrial stromal cells during the proliferative phase and that, at higher cell densities, stromal cells may synthesize specifically type I collagen predominantly during the secretory phase and during the first trimester of pregnancy, as a result of prolonged exposure to progestin. In the present study with a mAb against type VI collagen, type VI collagen was found to be localized diffusely in the human endometrium in a fine fibrillary pattern throughout the menstrual cycle and in the decidua in the first trimester. These findings are not consistent with the previously published data (Aplin of at., 1988; Mulholland et al, 1992). This microfibrillar collagen is an unusual and unique collagen, which may function as an anchor to the surrounding ECM (Bruns ot al., 1986; Keene et al, 1988). Mulholland et al. (1992) indicated that type VI collagen is lost from the rat endometrial stroma during decidualization, whereas this collagen begins to reappear in the ECM after the onset of regression of decidual cells, suggesting that type VI collagen plays a role in trophoblastic invasion. The results of our observations suggest the reappcarance of type VI collagen in the human decidual tissues. In the decidua, components of the basement membrane, such as type IV collagen and laminin, were apparently present around the decidual cells. This finding is in agreement with previous reports (Ulla ot al., 1985; Aplin of al, 1988). The accumulation of periceliular, basement membrane-like substances, including type IV collagen and laminin, may be associated with the process of decidualization of the endometrium. The basement membrane may be involved in selective permeability of macromolecules and structural 


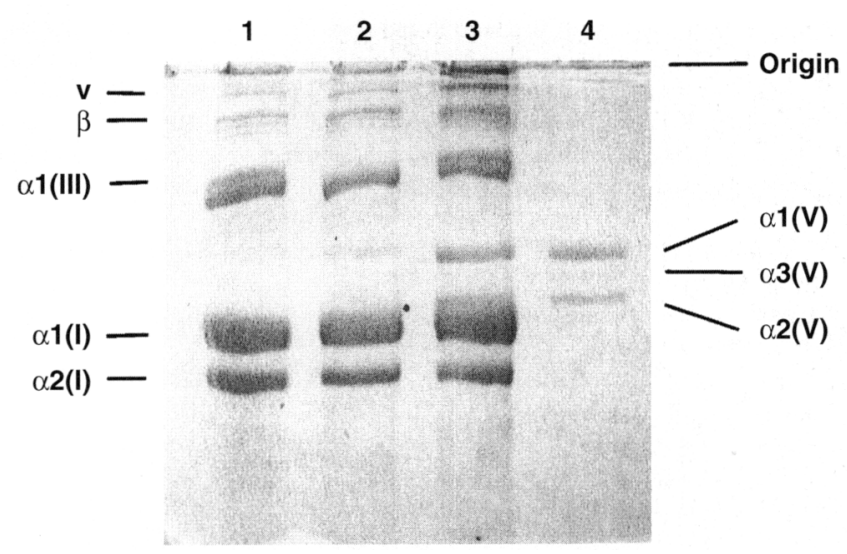

Fig. 4. SDS-PAGE of pepsin-solubilized human collagens from the proliferative-phase endometrium (lane 1), secretory-phase endometrium (lane 2), decidua (lane 3), and type $\mathrm{V}$ collagen extracted from the decidual tissues (lane 4). Samples of heat-denatured collagen ( $5 \mu \mathrm{g}$, lanes $1-3 ; 1.0 \mu \mathrm{g}$, lane 4 ) were subjected to electrophoresis on a slab gel for $1 \mathrm{~h}$. After reduction in situ with $\beta$-mercaptoethanol for $30 \mathrm{~min}$, electrophoresis was resumed for $1 \mathrm{~h}$. In this study, the $\alpha$ chains derived from type IV collagen could not be detected because of their low concentration in the sample. Note that the type $V$ collagen obtained from decidual tissue by differential salt precipitation was composed predominantly of the $\alpha \mathrm{I}(\mathrm{V})$ chain. (a)

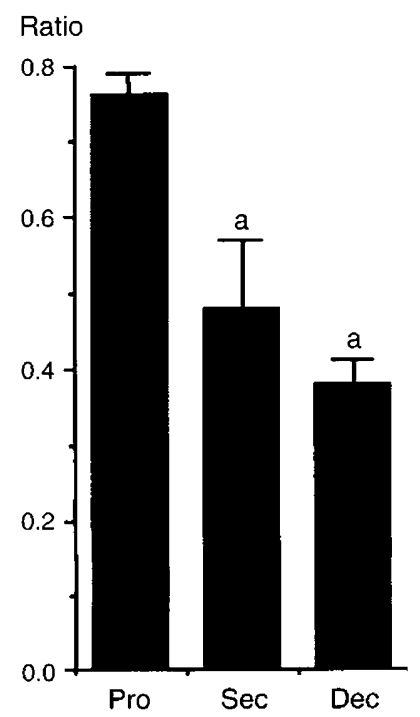

(b)

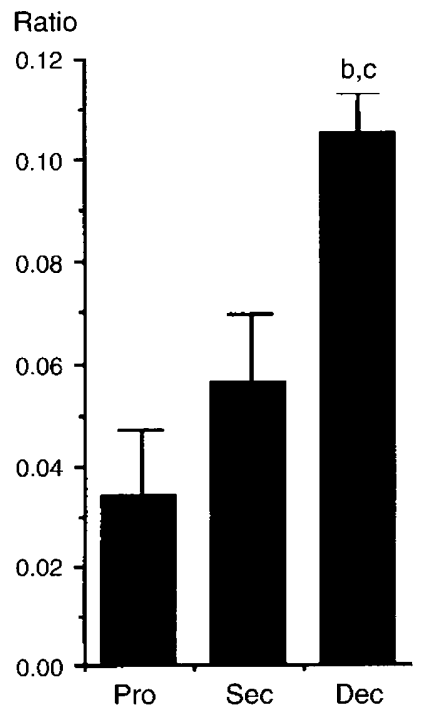

Fig. 5. Relative abundance of (a) the $\alpha I(I I I)$ and (b) the $\alpha 1(V)$ chains of human collagen as compared with the $\alpha 1(\mathrm{I})$ chain in the proliferativephase endometrium (Pro; $n=36$ ), the secretory-phase endometrium (Sec; $n=42$ ), and the decidua (Dec; $n=53$ ). Data are presented as the mean $\pm \mathrm{SEM}$. Values were analysed for the statistical significance of differences among the three groups by analysis of variance and Student's $f$ test. ${ }^{a} P<0.05$ versus the proliferative-phase endometrium, ${ }^{b} P<0.01$ versus the proliferative-phase endometrium, ${ }^{c} P<0.05$ versus the secretory-phase endometrium.

tissue-support. In contrast, laminin, which binds to itself, to type IV collagen, to heparin, and to cell-surface receptors, promotes the adhesion and growth of various epithelial and tumour cells (Kleinman et al., 1985; Martin and Timpl, 1987), as well as the outgrowth of neurites (Baron van Evercooren $e$ al. 1982). In addition, recent studies have revealed that the amino acid sequence of laminin exhibits considerable homology to that of epidermal growth factor-related (EGF-related) proteins (Gray et al., 1983; Sasaki et al., 1987, 1988) and that both EGF and laminin stimulate cell growth and differentiation (Carpenter and Cohen, 1979). Thomas and Dziadek (1993) demonstrated that the gene for laminin is expressed in the decidua during the peri-implantation period. These findings suggest that pericellular accumulated laminin modulates the functions of decidual cells in an autocrine or paracrine fashion.

In the present study, we investigated the immunolocalization of prolyl hydroxylase in the proliferative and secretory endometrium and in the decidua. Immunostaining for prolyl hydroxylase was clearly apparent in the cytoplasm of stromal cells, epithelial cells of endometrial glands, and endothelial cells of vessels. These findings suggest that stromal cells are mainly responsible for the synthesis of collagen in the endometrium. In the decidua, strong immunoreactivity was observed in the cytoplasm of the decidual cells, suggesting that decidual cells synthesize various types of collagen more actively than stromal cells in the proliferative and secretory endometrium. Prolyl hydroxylase was also localized in the epithelial cells of endometrial glands and, therefore, endometrial glandular cells may be involved in the synthesis of basement membrane collagen during the proliferation of endometrial glands. In the decidua, the disappearance of immunoreactivity for prolyl hydroxylase in the endometrial glandular cells may reflect the regression of endometrial glands. Prolyl hydroxylase, a key enzyme in the hydroxylation of proline to hydroxyproline during the synthesis of collagen (Rhoads and Udenfriend, 1970; Cardinale and Udenfriend, 1974), is a tetramer of two $\alpha$ and two $\beta$ subunits (Kivirikko et al., 1989). A cDNA sequence for the $\beta$ subunit of human prolyl hydroxylase has been found to be highly homologous with that for a rat protein disulfide isomerase, which is regarded as the catalyst in wivo for formation of disulfide bonds in the biosynthesis of various secretory proteins (Edman et al., 1989; Kivirikko et al., 1989). Therefore, the immunoreactivity of the $\beta$ subunit may reflect the enzymatic activity of prolyl hydroxylase in collagen metabolism.

In the case of type $\mathrm{V}$ collagen, the purified protein extracted from the decidua by differential salt precipitation was composed of $\alpha I(V), \alpha 2(V)$ and $\alpha 3(V)$ chains, and $\alpha I(V)$ was the predominant chain. The present study showed that the $\alpha 2(V)$ chain comigrated with the $\alpha 1(\mathrm{I})$ chain, and the $\alpha 3(\mathrm{~V})$ chain was almostly undetectable after SDS-PAGE. Therefore, the ratios of $\alpha I(I I I)$ and $\alpha I(V)$ calculated in terms of $\alpha \mathrm{I}(\mathrm{I})$ are likely to be something of an underestimate. Nevertheless, the marked increase in the intensity of the band of $\alpha 1(\mathrm{~V})$ was quite evident in the case of decidua. The most striking finding was a significant increase in the relative amount of type $\mathrm{V}$ collagen in the decidua as compared with that in the proliferative-phase and secretory-phase endometrium. Thus, it may be concluded that decidual cells, which are the major collagen-producing cells, synthesize predominantly type $\mathrm{V}$ and type I collagens and lower amounts of type III collagen. Increased relative amounts of type $\mathrm{V}$ collagen have been reported in atherosclerosis (Ooshima, 1981). Type V collagen has the ability to bind to 
insulin (Yaoi et al, 1991) and to heparin/heparan sulfate (Richard et al., 1989) with apparent higher affinity than collagen types I, II, III, IV, or VI, fibronectin, or laminin. Insulin bound to type $\mathrm{V}$ collagen has also been shown to retain mitogenic activity (Yaoi et al., 1991) and heparin/ heparan sulfate has been shown to modulate the biological activities of vascular endothelial cell growth factor (Lobb et al., 1986) and basic fibroblast growth factor (Thornton et al., 1983; Schreiber et al., 1985). These findings suggest that type $\mathrm{V}$ collagen is important in the compartmentalization, storage, stabilization, and modulation of the activities of various growth factors. Since type $\mathrm{V}$ collagen also binds to thrombospondin (Mumby et al., 1984), its interactions with thrombospondin and heparan sulfate may be important in the assembly of the ECM and in the regulation of its biological functions. Therefore, it is suggested that increased relative amounts of $\alpha I(V)$ or type $V$ collagen in the decidua provide a biochemical basis for functional regulation of the decidual cells.

The decidua is the specialized and highly differentiated endometrial stroma of pregnancy, and it is formed as a result of prolonged stimulation by oestrogen, progestin, and growth factors, in particular, transforming growth factor- $\beta$ (TGF- $\beta$ ) (Kauma et al., 1990; Dungy et al., 1991; Lea et al., 1992; Vuckovic et al., 1992) and platelet-derived growth factor (Surrey and Halme, 1991; Chegini et al., 1992) generated by the trophoblasts of the implanting blastocyst and/or maternal platelets during invasion by the trophoblasts of the endometrium and disruption of its vessels. In particular, TGF- $\beta$ has been reported to alter the synthesis and catabolism of matrix components and the expression of integrin (Roberts et al., 1990, 1992; Border and Ruoslahti, 1992; Wahl, 1992). In conclusion, interstitial collagens, including type I, III, and VI collagens, were found to be localized diffusely in the stroma of the human endometrium during the menstrual cycle and in the decidua. Decidualization of the human endometrium may be characterized by increased relative amounts of type $\mathrm{V}$ and type I collagens and pericellular accumulation of basement membrane components, such as type IV collagen and laminin, around the decidual cells. The results of the present study provide insight into the hormonal regulation of the ECM, suggesting that alterations in the distribution and the composition of the ECM during the process of decidualization play an important role in implantation, invasion of trophoblastic cells and the maintenance of pregnancy.

\section{References}

Aplin JD, Charlton AK and Ayad S (1988) An immunohistochemical study of human endometrial extracellular matrix during the menstrual cycle and the first trimester of pregnancy Cell and Tissue Research 253 231-240

Bai Y, Muragaki Y, Obata K, Iwata K and Ooshima A (1986) Immunological properties of monoclonal antibodies to human and rat 4-prolyl hydroxylase Journal of Biochemistry 99 1563-1570

Baron van Evercooren A, Kleinman HK, Ohno S, Marangos P, Schwarz JP and Dubois-Dalcq ME (1982) Nerve growth factor, laminin, and fibronectin promote neurite growth in human fetal sensory ganglia cultures Journal of Neuroscience Research 8 179-194

Border WA and Ruoslahti E (1992) Transforming growth factor- $\beta$ in disease: the dark side of tissue repair Journal of Clinical Investigation 90 1-7
Bruns R, Press W, Engvall E, Timpl R and Gross J (1986) Type VI collagen in extracellular, $100-\mathrm{nm}$ periodic filaments and fibrils: identification by immunoelectron microscopy Journal of Cell Biology 103 394-404

Campbell JH, Kocher O, Skalli O, Gabbiani G and Campbell GR (1989) Cytodifferentiation and expression of $\alpha$-smooth muscle actin mRNA and protein during primary culture of aortic smooth muscle cellis. Correlation with cell density and proliferative state Arteriosclerosis 9 633-643

Cardinale GJ and Udenfriend S (1974) Prolyl hydroxylase Adzances in Enzymology 41 245-300

Carpenter G and Cohen S (1979) EGF Annual Review of Biochemistry 47 251-276

Chegini N, Rossi MJ and Masterson BJ (1992) Platelet-derived growth factor (PDGF), epidermal growth factor (EGF), and EGF and PDGF beta-receptors in human endometrial tissues: localization and in vitro action Endocrinology $1302373-2385$

Daly DC, Maslar IA and Riddick DH (1983) Prolactin production during in vitro decidualization of proliferative endometrium American Journal of Obstetrics and Gynecology 6 672-678

Dungy LJ, Siddiqi TA and Khan S (1991) Transforming growth factor-beta 1 expression during placental development American Journal of Obstetrics and Gynecology 165 853-857

Edman JC, Ellis L, Blacher RW, Roth RA and Rutter WJ (1989) Sequence of protein disulfide isomerase and implications of its relationship to thioredoxin Nature 317 267-270

Furuto DK and Miller EJ (1980) Isolation of a unique collagenous fraction from limited pepsin digests of human placental tissue Journal of Biological Chemistry 255 290-295

Golander A, Zakuth V, Shechter Y and Spirer Z (1981) Suppression of lymphocyte reactivity in vitro by a soluble factor secreted by explants of human decidua European Journal of Immunology 11 849-851

Goodman LV and Majack RA (1989) Vascular smooth muscle cells express distinct transforming growth factor- $\beta$ receptor phenotypes as a function of cell density in culture Journal of Biological Chemistry 264 5241-5244

Gray A, Dull TJ and Ullrich A (1983) Nucleotide sequence of epidermal growth factor cDNA predicts a 128,000 -molecular weight protein precursor Nature $303722-725$

Halme T, Vihersaari $\mathbf{R}$ and Penttinen $\mathbf{R}$ (1986) Lysyl oxidase activity and synthesis of desmosines in cultured human aortic cells and skin fibroblasts: comparison of cell lines from control subjects and patients with Marfan syndrome or other annuloaortic ectasa Scandinavian Journal of Clinical and Laboratory Investigation 46 31-37

Haralson MA (1993) Extracellular matrix and growth factors: an integrated interplay controlling tissue repair and progression to disease Laboratory Investigation 69 369-372

Hulmes DJ (1992) The collagen superfamily - diverse structures and assemblies Essays in Biochemistry 27 49-67

Ishimura E, Sterzel RB, Budde $\mathbf{K}$ and Kashgarian $\mathbf{M}$ (1989) Formation of extracellular matrix by cultured rat mesangial cells American Journal of Pathology $134843-855$

Juan Cl, Martin MQ, David K, Ralph BL and Roger JB (1989) Hormonal regulation of human endometrial stromal cells in culture: an in vitro model for decidualization Fertility and Sterility 52 761-768

Kauma S, Matt D, Strom S, Eierman D and Turner T (1990) Interleukin-1 beta, human leukocyte antigen HLA-DR alpha, and transforming growth factor-beta expression in endometrium, placenta, and placental membranes American Journal of Obstetrics and Gynecology 163 1430-1437

Kearns M and Lala PK (1983) Life history of decidual cells: a review American Journal of Reproductive Immunology 3 78-82

Keene DR, Engvall E and Granville RW (1988) Ultrastructure of type VI collagen in human skin and cartilage suggests an anchoring function for this filamentous network Journal of Cell Biology 107 1995-2006

Kivirikko KI and Prockop DJ (1967) Hydroxylation of proline in synthetic polypeptides with purified protocollagen hydroxylase Journal of Biological Chemistry 242 4009-4012

Kivirikko KI, Myllyla R and Pihlajaniemi T (1989) Protein hydroxylation: prolyl 4-hydroxylase, an enzyme with four cosubstrates and a multifunctional subunit FASEB Journal 3 1609-1617

Kleinman HK, Cannon FB, Laurie GW, Hassel JR, Aumailley M, Terranova VP, Martin GR and Dubois-Deleq M (1985) Biological activities of laminin Journal of Cellular Biochemistry 217 317-325

Labat-Robert J, Bihari-varga M and Robert L (1990) Extracellular matrix FEBS Letters 268 386-393 
Laemmli UK (1970) Cleavage of structural proteins during the assembly of the head of bacteriophage T4 Nature 227 680-685

Lea RG, Flanders KC, Harley CB, Manuel J, Banwatt D and Clark DA (1992) Release of a transforming growth factor (TGF)-beta 2-related suppressor factor from postimplantation murine decidual tissue can be considered with the detection of a subpopulation of cells containing RNA for TGF-beta 2 Journal of Immunology 148 778-787

Lermioglu F, Goyal J and Hassid A (1991) Cell density modulates the decrease of cytosolic free $\mathrm{Ca}^{2+}$ induced by arterial natriuretic hormone, S-nitroso- $N$ acetylpenicilliamine and 8-bromo cyclic GMP in cultured rat mesangial cells Biochemical Journal 274 323-328

Lin CQ and Bissell MJ (1993) Multi-faceted regulation of cell differentiation by extracellular matrix FASEB Journal 7 737-74.3

Lobb RR, Harper JW and Fett JW (1986) Purification of heparin-binding growth factors Analytical Biochemistry 154 1-14

McCullagh KA and Balian G (1975) Collagen characterisation and cell transformation in human atherosclerosis Nature 258 73-75

Madri JA and Basson MD (1992) Extracellular matrix-cell interactions: dynamic modulators of cell, tissue and organisms structure and function Laboratory Investigation 66 519-521

Majors AK and Ehrhart L (1992) Cell density and proliferation modulate collagen synthesis and procollagen mRNA levels in arterial smooth muscle cells Experimental Cell Research 200 168-174

Martin GR and Timpl R (1987) Laminin and other basement membrane components Annual Review of Cellular Biology 3 57-85

Maslar IA, Kaplan BM, Luciano AA and Riddick DH (1980) Prolactin production by the endometrium of early human pregnancy Journal of Clinical Endocrinology and Metabolism 51 78-83

Miller EJ and Rhodes RK (1982) Preparation and characterization of the different types of collagen Methods in Enzymology 82 33-64

Mulholland J, Aplin JD, Ayad S, Hong L and Glasser SR (1992) Loss of collagen type VI from rat endometrial stroma during decidualization Biology of Reproduction 46 1136-1143

Mumby SM, Rauji GJ and Bornstein P (1984) Interactions of thrombospondins with extracellular matrix proteins: selective binding to type $\mathrm{V}$ collagen Journal of Cell Biology 98 646-652

Ooshima A (1981) Collagen $\alpha$ B chain: increased proportion in human atherosclerosis Science $\mathbf{2 1 3}$ 666-668

Ooshima A and Muragaki Y (1990) Collagen metabolism in atherogenesis Annals of the New York Academy of Sciences 598 582-584

Patton WF, Yoon MU, Alexander JS, Chung-Welch N, Hechtman HB and Shepro D (1990) Expression of simple epithelial cytokeratins in bovine pulmonary microvascular endothelial cells Journal of Cell Physiology 143 140-149

Pijnenborg R, Dixon G, Robertson WB and Brosens I (1980) Trophoblastic invasion of human decidua from 8 to 18 weeks of pregnancy Placenta $13-19$

Rhoads RE and Udenfriend S (1970) Purification and properties of collagen proline hydroxylase from newborn rat skin Archives of Biochemistry and Biophysics 139 329-339

Richard GL, Agneta H, Jeffrey DE, Steffen G and Magnus H (1989) Binding of heparan sulfate to type $\mathrm{V}$ collagen Journal of Biological Chemistry 264 7950-7956

Roberts AB, Heine UI, Flanders KC and Sporn MB (1990) Transforming growth factor- $\beta$ : major role in regulation of extracellular matrix Annals of the New York Academy of Sciences $\mathbf{5 8 0} 225-232$
Roberts AB, McCune BK and Sporn MB (1992) TGF- $\beta$ : regulation of extracellular matrix Kidney International 41 557-559

Rösner H, Greis C and Rodemann HP (1990) Density-dependent expression of ganglioside GM3 by human skin fibroblasts in an all-or-none fashion, as a possible modulation of cell growth in vitro Experimental Cell Research 190 $161-169$

Sasaki M, Kato S, Kohno K, Martin GR and Yamada Y (1987) Sequence of the CDNA encoding the B1 chain revealed a multidomain protein containing cysteine-rich repeats Proceedings of the National Academy of Sciences USA $\mathbf{8 4}$ 935-939

Sasaki M, Kleinman HK, Huber H, Deutzmann R and Yamada Y (1988) Laminin, a multidomain protein Journal of Biological Chemistry 263 16 536-16 544

Schreiber AB, Kenny J, Koalski WJ, Friesel R, Mehlman T and Maciag T (1985) Interaction of endothelial cell growth factor with heparin: characterization by receptor and antibody recognition Proceedings of the National Academy of Sciences USA 82 6138-6142

Strauss JF and Gurpide E (1991) The endometrium: regulation and dysfunction. In Reproductive Endocrinology: Physiology, Pathology, and Clinical Management (3rd Edn) pp 309-356 Eds SC Yen and RB Jaffe. Harcourt Brace Jovanovich, Philadelphia

Surrey ES and Halme J (1991) Effect of platelet-derived growth factor on endometrial stromal cell proliferation in vitro: a model for endometriosis? Fertility and Sterility 56 672-679

Sykes B, Puddle B, Francis M and Smith R (1976) The estimation of two collagens from human dermis by interrupted gel electrophoresis Biochemical and Biophysical Research Communications 72 1472-1480

Thomas T and Dziadek M (1993) Expression of laminin and nidogen genes during the postimplantation development of the mouse placenta Biology of Reproduction 49 1251-1259

Thornton SC, Mueller SN and Levine EM (1983) Human endothelial cells: use of heparin in cloning and long-term serial cultivation Science 222 623-625

Tsonis PA and Goetinck PK (1990) Cell density effects of a tumor promotor on proliferation and chondrogenesis of limb bud mesenchymal cells Experimental Cell Research 190 247-253

Ulla MK, Mette F, Lance AL and Reidar A (1985) Immunochemical and ultrastructural assessment of the nature of the pericellular basement membrane of human decidual cells Laboratory Investigation 53 624-633

Van der Rest M and Garrone $\mathbf{R}$ (1991) Collagen family of proteins FASEB Journal 5 2814-2823

Vuckovic M, Genbacev O and Kumar S (1992) Immunohistochemical localization of transforming growth factor-beta in first and third trimester human placenta Pathobiology $60149-151$

Wahl SM (1992) Transforming growth factor beta (TGF- $\beta$ ) in inflammation: a cause and a cure Journal of Clinical Immunology 12 61-74

Worthuis A, Boes A and Grond J (1993) Cell density modulates growth, extracellular matrix, and protein synthesis of cultured rat mesangial cells American Journal of Pathology 143 1209-1219

Yaoi Y, Hashimoto K, Takahara K and Kato I (1991) Insulin binds to type V collagen with retention of mitogenic activity Experimental Cell Research 194 180-185 